\title{
PERANCANGAN PERANGKAT LUNAK VISUAL NOVEL PERISTIWA BANDUNG LAUTAN API
}

\author{
Jason Jiv Matatula ${ }^{1}$ \\ Yusup Jauhari Shandi ${ }^{2}$ \\ Sekolah Tinggi Manajemen Informatika dan Komputer LIKMI \\ Jl. Ir. H. Juanda No. 96 Bandung \\ ujshandi@gmail.com ${ }^{2}$
}

\begin{abstract}
ABSTRAK
Di era modern saat ini, dunia game dan teknologi mengalami perkembangan yang sangat pesat termasuk dalam dunia PC game. Dari sekian banyak game yang menyajikan fitur, kualitas, visualisasi maupun alur cerita game itu sendiri, terdapat game yang tetap memakai konsep kesederhanaannya, yakni visual novel. Pengembang game lokal yang memproduksi visual novel lebih banyak dipengaruhi oleh gaya anime dan manga dari Jepang.

Artikel ini memaparkan perancangan visual novel Peristiwa Bandung Lautan Api (PBLA). Pemodelannya memanfaatkan beberapa diagram UML. Pengembangan perangkat lunak menggunakan metode prototyping. Program dibuat dengan perangkat Unity Engine dan C\#. Visual novel ini diharapkan dapat meningkatkan kesadaran pemain dan pengembang game lokal betapa bagusnya sejarah di Indonesia, khususnya peristiwa heroik Bandung Lautan Api, sehingga bisa mendorong lebih banyak lagi pengembang game lokal yang membuat visual novel.
\end{abstract}

Kata kunci : visual novel, Unity Engine, Peristiwa Bandung Lautan Api

\section{PENDAHULUAN}

Dunia game dan teknologi mengalami perkembangan yang sangat pesat termasuk dalam dunia PC game. Dari sekian banyak game yang menyajikan fitur, kualitas, visualisasi maupun alur cerita, terdapat juga game yang tetap memakai konsep kesederhanaannya, yakni visual novel. Banyaknya penggemar game jenis ini tidak hanya di Jepang, tetapi di seluruh dunia. Visual Novel sebagai game fiksi interaktif yang menampilkan gambar statis menggunakan gambar anime, foto atau bahkan lukisan mirip dengan rekaman video dan menyerupai media campuran [4].

Namun bertolak belakang dengan kesuksesan dan perkembangan teknologi visual novel, ternyata masih menunjukkan terbatasnya pengembang game lokal yang memproduksi visual novel tentang sejarah Indonesia. Selain itu, produksi visual novel di Indonesia juga lebih banyak dipengaruhi oleh gaya anime dan manga dari Jepang. Padahal visual novel adalah cikal - bakal bagian dari produk industri kreatif yang bisa menjadi potensial [5].

\section{GAME ENGINE DAN VISUAL NOVEL}

Visual novel (dalam bahasa Jepang : bijuaru noberu) atau yang terkadang disebut sound novel adalah jenis permainan interaksi fiksi yang dapat dimainkan di komputer PC maupun konsol. Game ini berbasis fiksi interaktif yang menampilkan cerita novel dalam bentuk gambar dan dilengkapi dengan kotak percakapan untuk menyampaikan narasi dan ucapan setiap karakter, bahkan setiap karakter memilki pengisi suara tersendiri. 
Visual novel termasuk salah satu jenis permainan petualangan, yang difokuskan di bagian penceritaan, sehingga pemain seringkali hanya membaca novel di komputer pribadi yang menampilkan gambar beserta teks dan suara. Seringkali pemain diharuskan untuk memilih di antara pilihan-pilihan yang ada untuk melanjutkan ke jalan cerita selanjutnya, dan setiap pilihan yang diambil dapat memengaruhi jalan cerita dari visual novel yang sedang dimainkan. Kebanyakan visual novel memiliki beberapa alur cerita dan banyak akhir cerita. Mekanisme gameplay dalam kasus ini biasanya terdiri dari poin keputusan pilihan ganda intermiten, dimana pemain memilih sebuah arah dimana untuk mengambil permainan.

Untuk mengembangan program visual novel PBLA, akan memanfaatkan perangkat Unity Engine. Software ini merupakan salah satu game engine yang sangat populer dan banyak dimanfaatkan para pengembang produk game.

Menurut Jared Halpern [2], game engine adalah : "Soffware development tools designed to reduce the cost, complexity, and time-to-market required in the development of video games." Game engines ini memberikan manfaat dalam hal efisiensi dengan menggali kedalaman pegetahuan yang dibutuhkan untuk membuat game. Developer bisa meminimalkan pengerjaan fungsionalitas prebuilt atau fitur lengkapnya, sehingga memungkinkan untuk fokus sepenuhnya pada penulisan kode game. Game engine menawarkan keunggulan terbaik dibandingkan memulai dari awal untuk developer tunggal atau tim yang harus fokus membuat game terbaik.

\section{SEJARAH SINGKAT PBLA [1]}

Setelah didahului oleh kedatangan misi pengintai yang dipimpin oleh Kapten Gray dan Kapten Clark, pasukan pertama Sekutu mulai memasuki kota Bandung pada tanggal 12 Oktober 1945. Kedatangan mereka menyampaikan beberapa tuntutan, yang tentu saja ditolak oleh para pejuang. Dan akhirnya konflik bersenjata pun terjadi. Kekuatan sekutu yang memasuki kota Bandung ini terdiri dari satu Brigade RAPWI (Recovery of Allied Prisoners of War an Internees) yang dipimpin Brigjen Mc.Donald.

Tanggal 27 November 1945, Brigjen Mc.Donald menyerahkan ultimatum pertama. Brigjen Mc.Donald memanggil Gubernur Jawa Barat Sutarjo Kartohadikusumo ke markas besar tentara Inggris didaerah Bandung Utara untuk menyerahkan ultimatum yang ditujukan kepada penduduk kota Bandung. Maksud ultimatum tersebut adalah agar rakyat dan semua pasukan bersenjata, baik TKR maupun Laskar Perjuangan keluar dari wilayah Bandung Utara, paling lambat pukul 12.00 siang pada tanggal 29 November 1945. Setelah batas akhir ultimatum terlewati, resmi sejak saat itu kota Bandung terbagi dua, Bandung Utara dan Bandung Selatan. Bandung Utara menjadi wilayah Sekutu, sedangkan Bandung Selatan menjadi wilayah Republik Indonesia

Panglima tertinggi AFNEI di Jakarta Letnan Jenderal Montagu Stophord, memberikan ultimatum kedua pada tanggal 17 Maret 1946 kepada Perdana Menteri Sutan Sjahrir, supaya memerintahkan pasukan bersenjata RI meninggalkan Bandung Selatan sampai radius $11 \mathrm{~km}$ dari pusat kota. Batas Ultimatum adalah pada 24 Maret 1946 pukul 24.00. Apabila ultimatum tersebut tidak dilaksanakan Inggris akan membombardir Bandung Selatan.

Pagi hari menjelang terjadinya PBLA, Kolonel A.H. Nasution mengadakan rapat dengan sejumlah komandan tentara di Markas Divisi III TRI. Terjadi kesimpangsiuran karena mereka menerima dua perintah yang berbeda dari Pemerintah RI di Jakarta dan dari MBT (Markas Besar Tentara) di Jogjakarta. Hasil pertemuan tersebut mengambil jalan tengah di antara kedua perintah, yakni meninggalkan kota Bandung bersama seluruh pemerintah sipil dan rakyat, serta melakukan infiltrasi dan aksi bumi-hangus di daerah Bandung Selatan, khususnya terhadap bangunan vital agar tidak dapat digunakan oleh Sekutu. 
Tanggal 24 Maret 1946 pukul 20.00 terjadi ledakan pertama yang tidak sesuai rencana. Setelah sebagian besar penduduk mengungsi ke luar kota Bandung, maka tiba pada pelaksanaan rencana lainnya, yakni membumihanguskan kota Bandung. Sebagai akibat kurangnya koordinasi, aksi bumihangus yang semula baru akan dilaksanakan pada pukul 24.00 ternyata sudah berjalan sejak pukul 20.00. Ledakan pertama di Gedung Indische Restaurant yang terbilang lebih cepat dari rencana, sontak menimbulkan kepanikan diantara para pejuang lainnya. Akibatnya, cukup banyak bangunan vital yang gagal diledakan. Namun demikian, aksi bumihangus terus berlangsung, khususnya terhadap rumah-rumah tinggal, jadilah pada malam hari itu, Bandung bagaikan lautan api.

\section{PERANCANGAN VISUAL NOVEL PBLA}

Untuk memetakan kebutuhan visual novel PBLA, digunakan use case diagram. Setiap proses utama akan ditampilkan berupa use case. Gambar 1 menampilkan use case diagram. Rincian alur proses digambarkan modelnya berupa activity diagram (Gambar 3). Sedangkan untuk perancangan atribut data dan prosedur (behaviour) akan memanfaatkan class diagram (Gambar 2).

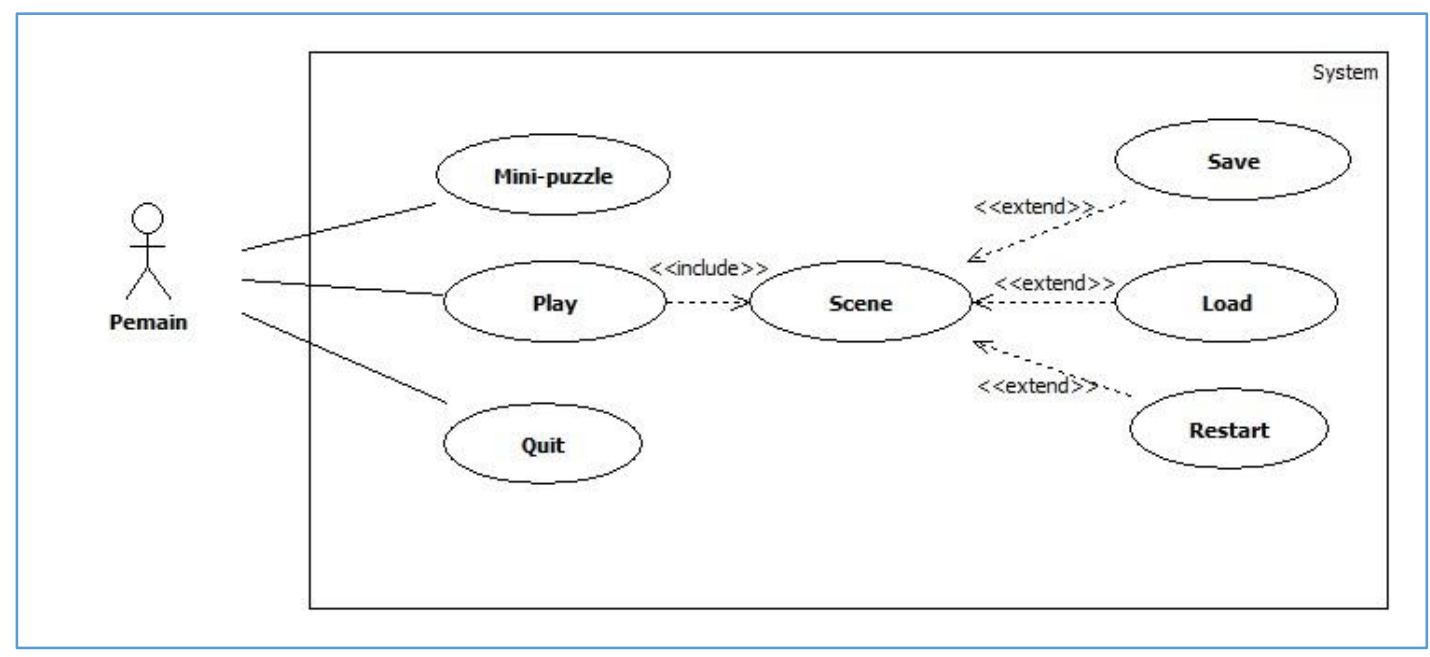

Gambar 1

Use Case Diagram

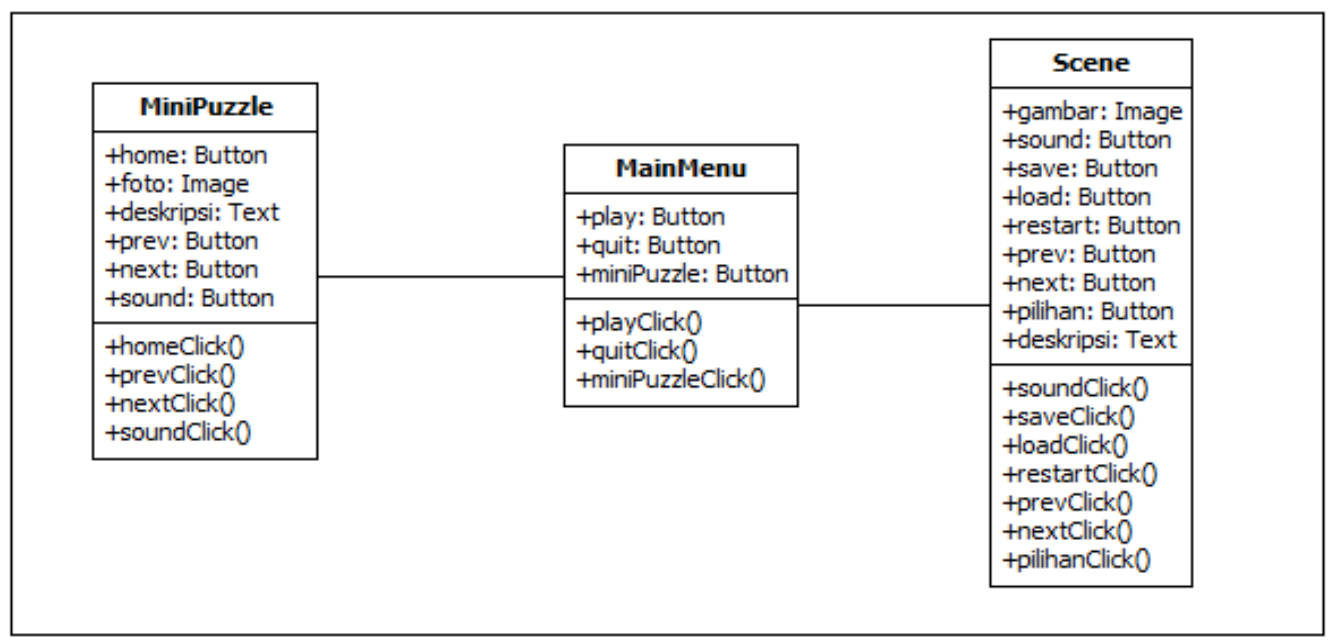

Gambar 2

Class Diagram 


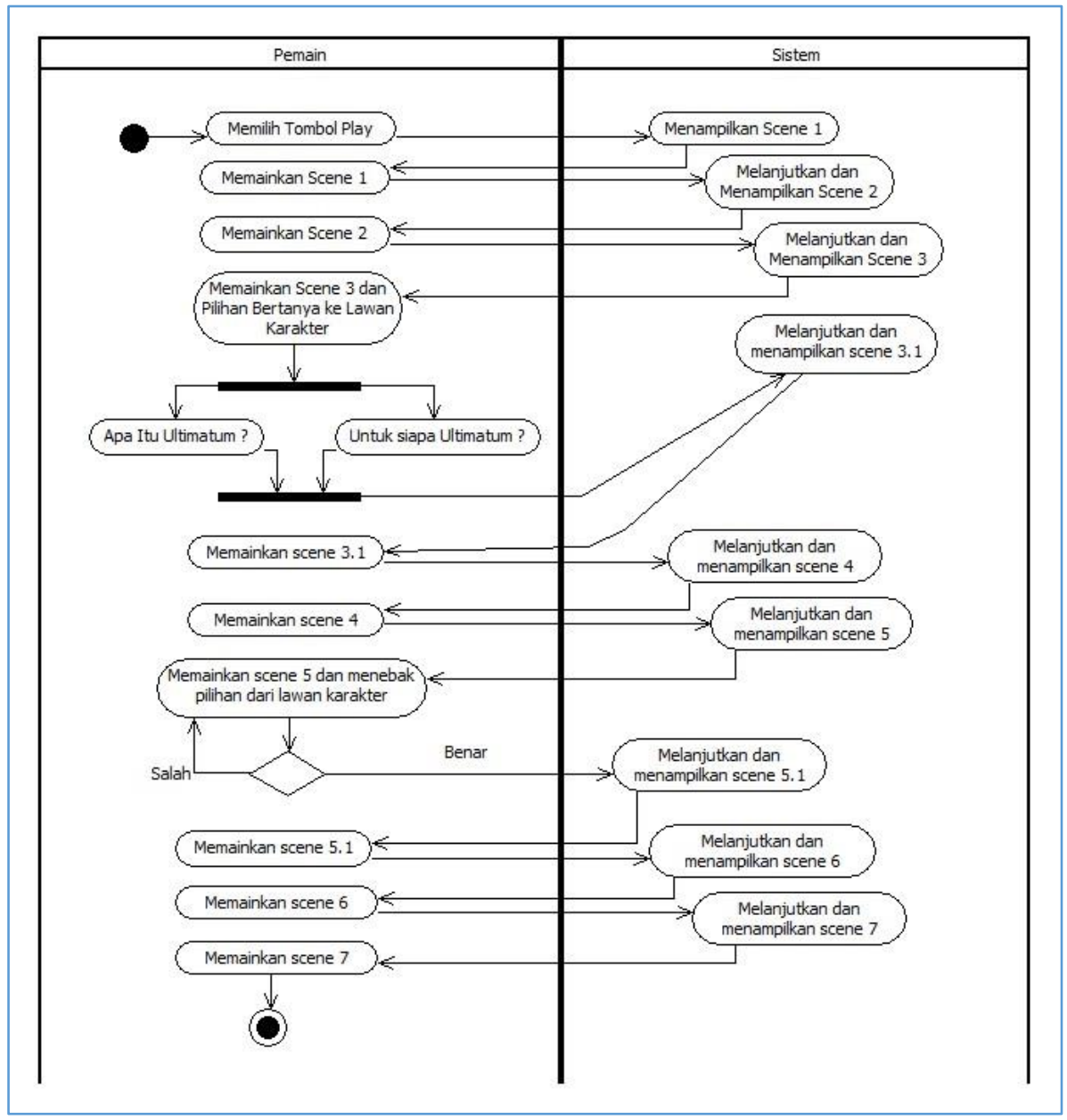

Gambar 3

Activity Diagram

\section{ANTAR-MUKA PROGRAM}

Berikut ini ditampilkan 4 (empat) buah rancangan antar-muka program. Gambar 4 merupakan antar-muka menu utama program. User bisa memilih tombol PLAY untuk memulai permainan utama, memilih tombol MINI-PUZZLE untuk mencoba permainan puzzle PBLA, atau memilih tombol QUIT untuk keluar/mengakhiri program.

Gambar 5 adalah tampilan awal untuk memulai permainan utama.Screen dilengkapi dengan 3 (tiga) buah tombol, yaitu SAVE (untuk menyimpan data permainan jika belum berakhir), tombol LOAD (untuk mengambil kembali data permainan yang sudah tersimpan), serta tombol RESTART (untuk melakukan restart/ membatalkan permaianan yang tengah berlangsung tanpa disimpan).

Gambar 6 menampilkan antar-muka untuk bertanya dan menebak pilihan dari karakter lawan. Sedangkan Gambar 7 merupakan antar-muka untuk permainan mini-puzze. Mula-mula akan ditampilkan sekumpulan potongan foto PBLA secara acak. User diminta menyusun foto-foto pada posisi yang sesuai. 


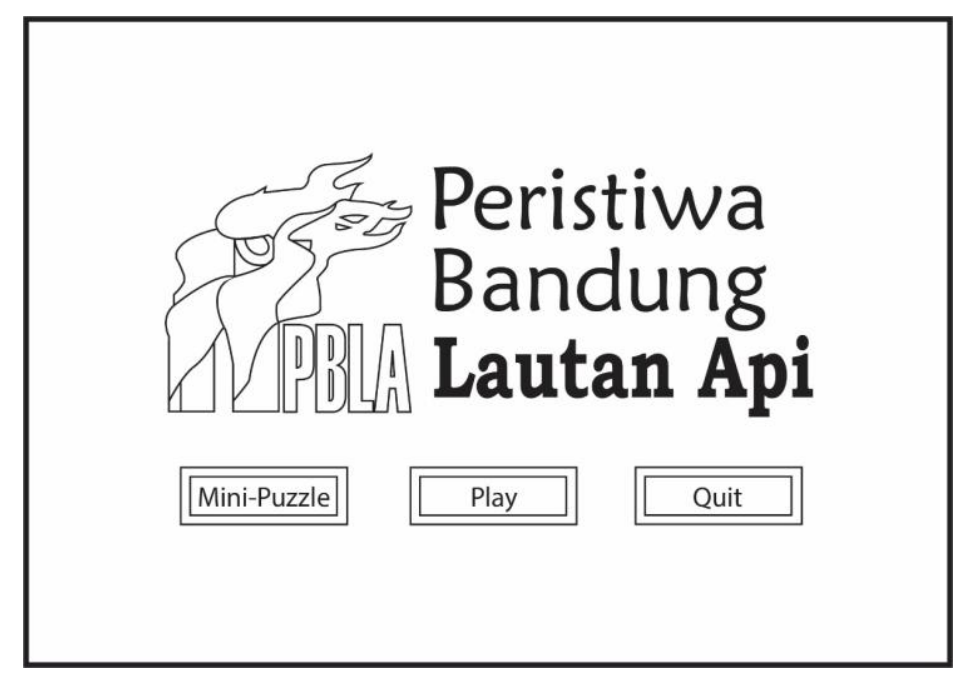

Gambar 4

Antar-muka Menu Utama Program

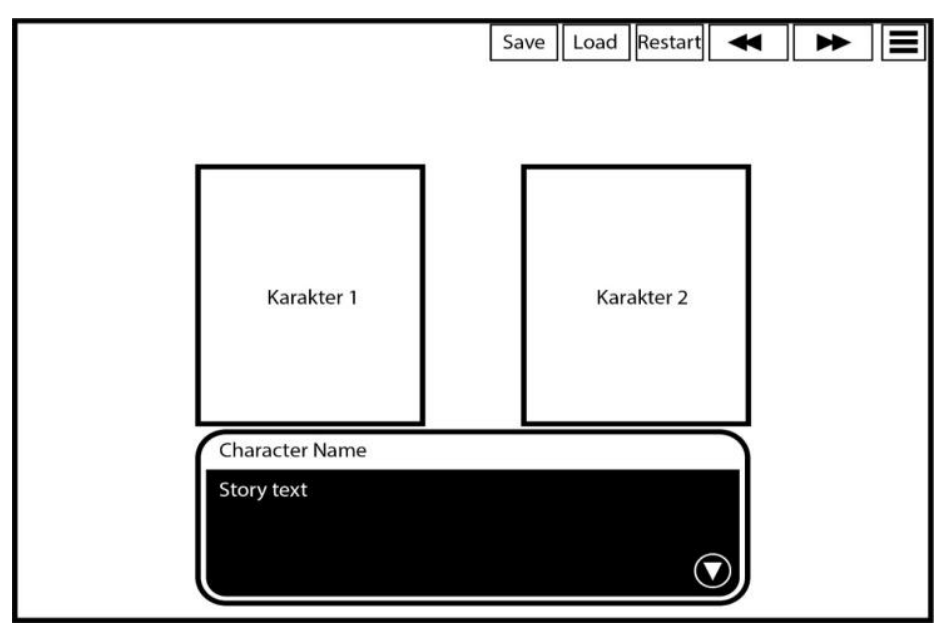

Gambar 5

Antar-muka Mulai Permainan

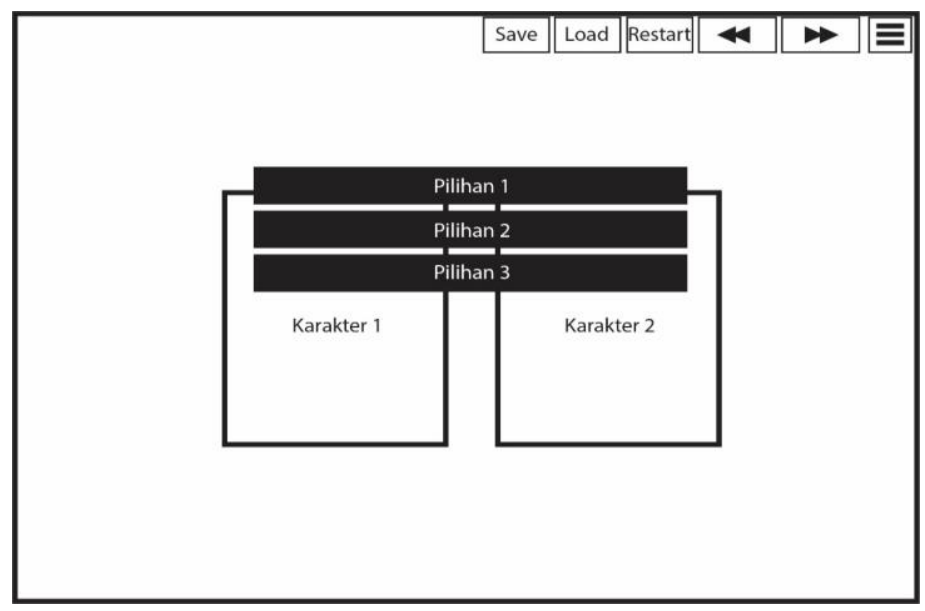

Gambar 6

Antar-muka Pilihan Bertanya dan Menebak Pilihan 


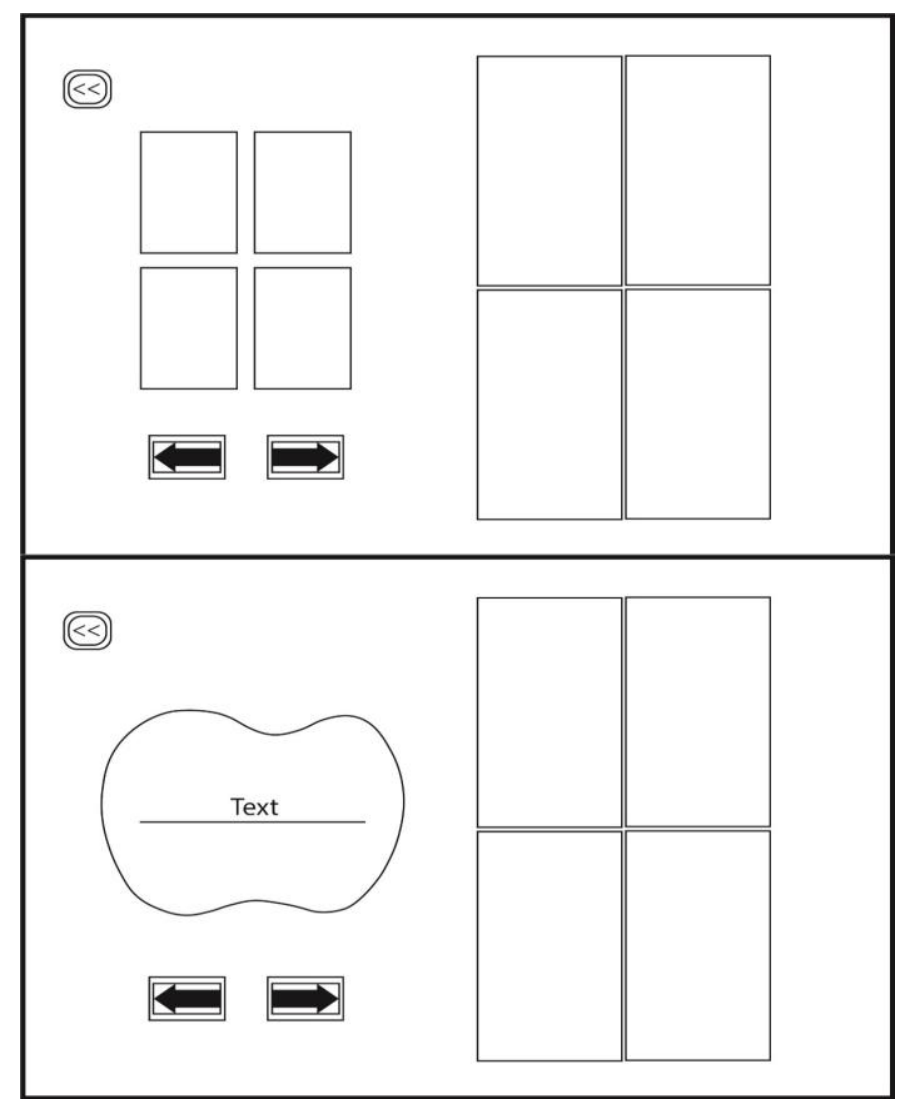

Gambar 7

Antar-muka Permaian Mini Puzzle

\section{KESIMPULAN}

Pengembangan perangkat lunak visual novel Peristiwa Bandung Lautan Api dapat berjalan dengan baik menggunakan $\mathrm{C \#}$ dan Unity Engine. Perangkat ini dapat membantu kita menggunakan assets berupa teks, gambar, suara, dan script yang diperlukan dalam mengembangkan visual novel Peristiwa Bandung Lautan Api, sehingga program permainan yang dihasilkan menjadi lebih menarik, mudah dipahami, dan dapat dijalankan pada perangkat komputer.

Produk visual novel PBLA diharapkan mendorong para pengembang game lokal untuk mengeksplorasi kekayaan sejarah nasional kita sebagai bahan tematik dalam membuat karya visual novelnya.

\section{DAFTAR PUSTAKA}

[1] Erianto, Dwi. (2021). Sejarah Peristiwa Bandung Lautan Api. Jakarta : Kompaspedia.

[2] Halpern, J. (2019). Developing 2D Games with Unity - Independent Game Programming with C\#.

[3] Ichsan, M., \& Qamaruzzaman, M. H. (2019). Rancang Bangun Permainan Misi Panglima Batur Menggunakan Engine Scirra Construct 2. Jurnal Sains Komputer Dan Teknologi Informasi, https://doi.org/10.33084/jsakti.v1i2.870

[4] Krisnandini, F., \& Taufiq Lutfhi, E. (2014). Aplikasi Game Novel Visual "Petualangan Di Tanah Jawa” Menggunakan Ren'py. Jurnal Teknik Informatika.

[5] Pratama, D., Gunarti, W., \& Akbar, T. (2017). Understanding Visual Artwork of Visual. MUDRA Journal of Art and Culture. 